\title{
INTERVIEW WITH TERRY EAGLETON
}

\section{Patrice Petro and Andrew Martin}

TERRY EAGLETON Is one of Britain's foremost literary critics and an internationally renowned Marxist scholar. He is a lecturer in English at the University of Oxford and a Fellow of Wadham College. He is also the author of numerous articles, far too numerous to list here, and of the following books: Shakespeare and Society (1967), Exiles and Emigres (1970), Myths of Power: A Marxist Study of the Brontës (1975), Marxism and Literary Criticism (1976), Criticism and Ideology (1976), Walter Benjamin: Or Towards a Revolutionary Criticism (1981), The Rape of Clarissa: Writing, Sexuality, and Class Struggle in Samuel Richardson (1982), Literary Theory (1983), The Function of Criticism (1984). As an Ida Beam Lecturer, Eagleton recently delivered three addresses at the University of Iowa during September 1984: "Criticism and the Public Sphere," "Marx or Derrida," and "The Future of Criticism." The following interview was conducted during Eagleton's stay in Iowa.

I wonder if we might begin by discussing the milieu in which you developed as an intellectual and critic. Perhaps you could also tell us a bit about your relationship with Raymond Williams, since his working class background and experiences at Cambridge seem in many ways similar to your own.

I came from Salford, which is near Manchester, and my grandparents had come over to the mill towns of Lancashire as part of the great Irish migration. During the Depression they moved into the cities and eventually ended up in Salford. So my parents were first generation English, although still with a strong Irish cultural background. My father was an engineering worker in what were then the largest engineering works in the country.

It was highly unusual in those days for someone to come from that kind of background, from what was then a grammar school, to Cambridge. I went to Cambridge in 1961 and was, I suppose, thoroughly traumatized by it culturally in a way not dissimilar to the experiences of Raymond Williams. In those days Cambridge was even more visibly a bastion for upper class culture than it is today. There was a small percentage of working class students, students who were very much on the defensive, very much of an 
enclave. Political activity was obviously one way out. At the time it would have been mainly the early nuclear disarmament movement, something I became involved with at Cambridge. There was also a Labour Club, although it was run largely by ex-public school marxists-Etonian marxists!and so a certain amount of interesting friction existed between, as it were, the genuine "prols" and those who had gone over to their side.

I met Williams while I was an undergraduate. He had come to Cambridge as a Fellow of Jesus College the same year I did and he seemed to me, as I first encountered him in lectures, to be the only member of the faculty to be talking any sort of language I could recognize. He was, to be precise, simply discussing literature in a way I found at once very difficult and unaccustomed to and yet which seemed to plug into what I felt I knew. So, when I graduated from Cambridge in 1964, Williams invited me to become a Research Fellow at his college and I taught there with him until 1969 when I left for Oxford.

That was a very interesting period because it meant that I lived through the various political developments in the 1960 s really actively working with Williams and with a number of students such as Stephen Heath and Colin MacCabe, for instance, who have since become well-known. So quite a lot came out of that period. But I think one problem was that Williams, while enormously influential on my development-and certainly I think he was the single most important intellectual, political, and in many ways moral influence on me at the time-had himself had a curious career. He had been in adult education and come in from that to the university fairly late. He had actually been offered a Fellowship on the basis of his Culture and Society. He never really adjusted to academia, however, and there was a moment in the late 1960s when he had around him a group of radical socialist students and critics who would have very much liked to organize some kind of intervention into the Cambridge English Faculty, had he given the word. But I think the irony was that Williams himself had had to learn to work independently and he was, in a certain sense, properly weary of what had happened to Scrutiny. And there seemed the possibility that a similar situation, although certainly more political, could have occurred again and Williams did not want to be involved in that. The various people around him then moved off to other places, mainly the red brick or new universities in Britain. And I moved to Oxford in 1969, partly because I still preserved much of the pathological antipathy to Cambridge, which I felt from the outset, and partly because, having worked in a tremendously productive way with Williams, I wanted to see how I could run things on my own. It was also becoming clear that the Cambridge English Faculty would not in fact give me a lectureship which, in those days at least, was necessary for financial reasons. (As a Fellow of the College I did some teaching but I was not a Lecturer.) Part of their refusal was, I think, an indirect attack on Williams himself, as I was identified with him. He was too powerful and influential a figure to be 
directly assaulted, although one or two of his colleagues and students were not. In a curious way, that was an earlier version of the later situation known as the MacCabe Affair, although it never reached such dramatic proportions.

Until about 1968 or 1969, you were clearly engaged with questions orginally raised by Williams in Culture and Society and The Long Revolution. In the late sixties and early seventies, however, you shifted your concerns towards developments within French theory. Would you explain this shift in terms of contemporary political or social events?

Looking back at the time it felt simply like moving from one body of theory to another, although one can see now the political determinants of that move. As the political scene was quickening in Europe and in the United States, and as new bodies of theory were developing, there was a younger generation of socialists, of which I was one, who then felt that the older New Left, of which Williams was a prototype, was neither sufficiently theoretically rigorous nor sufficiently politically engaged. I think my own movement towards marxism dates from that period. Certainly I don't think I would have called myself a marxist when I first came to Cambridge, but I clearly would have by the middle to late sixties. In an interesting way, I think that if one looks at the whole trajectory, what happened is that a number of us moved into what we took to be a more rigorous and in some ways more politically relevant form of theory and, from that perspective, it looked as though Williams was standing still, or perhaps even regressing. But it is dangerous to think you have preempted or got beyond Williams because he has a curious knack of, by apparently standing still, actually holding a position which you end up endorsing, or at least some version of it. And it is interesting if one looks at the way the theory of politics has developed since then: into forms of French or Althusserian marxism in the late sixties and early seventies and then out again in the very changed conditions of the later seventies. Williams was in a sense prefiguring, in much of his work, the kinds of positions and forms of allegiance that people might now find themselves with. I would not want, however, to simply negate the sort of critique of Williams's work that I wrote in Criticism and Ideology. I think that a lot of that critique, theoretically speaking, still stands. But what I did not see then, and what I have come to see since because of developing conditions, is not a matter of theoretical difference with Williams but rather agreement with the political force of his work: his attitude towards the critic's role in the academy, his attitude about what literary criticism should be, and even his stance toward cultural studies and the need to transgress disciplinary boundaries. All of that was strikingly present in Williams's work, at least in embryonic form, from the outset. And it is those elements of Williams's work that people like myself are now returning to under different conditions, and they are really more important than the kinds of theoretical or doctrinal distinctions that we had previously. I would just add, as a final 
note, that Williams himself, of course, hasn't actually stood still since the sixties either. Williams is much closer to marxism now than he ever was, apart from the very brief, and not very fortunate, period of his active membership in the Communist Party as a student. I think that Williams's work is, so to speak, effectively and objectively marxist work, whatever label we might strategically use for that.

Your valorization of Williams's work nevertheless seems to me surprising, since, as you have indeed noted, Williams works in isolation from not only the academy but also from what might potentially develop into a counter-public sphere. How, then, is he able to be as politically effective as you suggest?

It is a strong part of Williams's image, that quality of isolation. There is a sense in which he has been a kind of éminence grise on the left in Britain, and largely with very positive effects, although of course with some very negative ones as well. But what I realize now, more strongly that I did before, is that Williams is himself aware of his own isolation and actually makes this clear in his interview with New Left Review in Politics and Letters. His own isolation is very much the effect of a counter-public sphere, as it were, failing to come into existence. And I was struck by the way he talked, in very distanciating terms, about his earlier work in Culture and Society because he identified the political moment, the historical moment, as being for him very negative. What then happened, as the 1960s and 1970s drew on, was the emergence of new political developments in which Williams was involved. Certainly the resurgence of the New Left around the peace movement and the various kinds of interventions during the period of the Labour government of the 1960s were part of this. And even today Williams has played an active part in the organization in Britain called the "Socialists' Society," which is an attempt to organize intellectuals of various kinds and to put their work at the service of the trade union movement and the Labour movement generally. So he has had that history of involvement, but I think that at the same time the sense of the earlier dissociation remained and proved something that he could never truly get beyond. But I think it is interesting to put the problem not only, as it were, psychologically, but also in terms of the failure of the emergence of the material conditions which could have made Williams an even more influential figure than he has been.

It sounds like Politics and Letters contains many revelations for you, in spite of the fact that you worked very closely with Williams during those years.

Yes, part of Williams's political isolation, and his isolation in the academy, was the result of what we might politely call a rather civilized or enigmatic discourse. And indeed there were ways I took this on in my critique of him in Criticism and Ideology, ways in which his very style of discourse was related to that isolation. That is, somebody who is speaking, and for a long time was forced to speak, a language that was not popular, which could easily be 
misinterpreted, and what was also, to some degree, a language of selfprotection. I am therefore struck by the way that of all his work, Politics and Letters is the one in which he is the most candid, where in the company of comrades, so to speak, he talked openly about his career. One other point about Williams which is relevant is that I think it is a mistake to search, as often people have done, for the private man behind the public persona, because Williams has always been someone who sees his life in historical terms and in often quite distanciating ways. If there are losses in that or problems, problems of accountability, there have also been some gains. Williams has been able to solve or negotiate certain problems by himself by seeing them as historical necessities-while never once being fatalistic. One of the other important things about his work as a whole, although it often has a steely realism about it, is that he has never succumbed to the various tides of fashionable post-marxist pessimism, which from time to time drift around our societies.

An interesting thing about Williams is his attraction for American culture. But there is a tension in his view of America as at once an ideal and at the same time as a certain political reality, particularly vis-à-vis Britain.

Yes, Williams has been notable for his ability to remember the progressive moments within the most negative of cultures or bodies of thought. After all, Culture and Society was, among other things, the record of a highly conservative line of thought from which, by some feat of dialectics, Williams was able to abstract a positive moment. He has always had that intellectual and political breadth of vision and, in terms of his response to American culture, it marks him off from, say, the Frankfurt School, where the assumption of a much more one-sided attitude towards contemporary capitalist culture is prevalent. Sometimes I think Williams has been seen as overcharitable in that respect, sometimes moving close to left-liberalism. But then he also has been from the very start a genuinely dialectical thinker, with a genuinely dialectical cast to his work which has always sought to start, as Brecht put it, from the bad new things rather than the good old things.

The concept of the "disinterested" intellectual is ever present in the contemporary academy, at once an ideal, a standard to be met, but also a way of maintaining an atomized university structure. You trace this position in Literary Theory back to the Victorian "man of letters." Why do you think this ideal continues to have such force in the present-day academy?

I think that notions of disinterestedness begin to crop up in the 18th century with what Jürgen Habermas calls the emergence of the bourgeois public sphere, and what is striking about that disinterestedness is its obvious interestedness. That is to say, only those who have an "interest" can be disinterested, only those who have a stake in the culture, who are propertied, have a title to enter into a certain "disinterested" form of discourse-the whole 
discourse of the Enlightenment, for example. So what one is looking at in that whole history becomes visible as a highly elitist and exclusionist class formation-although certainly one which, like many class formations, needs to cast its language in universal terms. The role of disinterestedness is most forcefully understood today in terms of that history. What happens with the growth of the commodification of literature, which was taking place throughout the 18th century, is that there is now a sense, because of the existence of the text or writing as a commodity, in which literature is in principle available to everybody-whatever the actual restrictions of social access to literature and power. Nonetheless, the commodification of literature (and this is a reversion to a dialectical position held by Williams) actually liberates literary production from a very specific range of interested institutions - the court and organized religion, for example-when it was a part of the previous feudalist, absolutist epoch, only to abandon it to the market place. Ironically, then, and by a striking contradiction, the very possibility of disinterestedness as a critical concept, as an intellectual posture, depends upon a sort of promiscuous availablity of the literary commodity. Anybody is capable of judging it, any "gentleman" that is. And this situation itself, in turn, is an effect of commodity production. If one looks at the history in that way, then one sees where the so-called disinterested intellectual comes from. What I've tried to do in my lectures and in The Function of Criticism is to go on to trace the destiny of the concept into the 19th century and beyond. I think that the great crisis, the crisis around Matthew Arnold, for example, is, among other things, that it becomes implausible either to believe that you can transcend sectional and social interests (because the conflicts between those interests have intensified) or to believe that there is any longer a total body of social and intellectual knowledge on which intellectuals can get a fix, as it were, transcendentally. And it seems to me that one of the problems that dogged the institution of criticism, and no doubt a plurality of intellectual areas, is that either you try fruitlessly to reproduce that role of the disinterested intellectual, in all its various liberal humanist guises, or you candidly recognize that the role is now historically devaluated, it is past, and you try to do something else. The problem is that what that "something else" is tends either to be a kind of craven way for criticism, a kind of technocracy, a specialized, professionalized technocracy which has abandoned any hope of speaking more relevantly to a society beyond the academy, or, as with the left, you try and work out some other kind of sets of functions for criticism. I don't think criticism has solved that problem yet, and as long as it doesn't follow the path of the left, I think it is actually structurally incapable of doing so.

The role of the "disinterested" intellectual seems to have taken on a new function during the Cold War, or perhaps more properly, during the McCarthy Era, when Daniel Bell, Arthur Schlesinger and others were tolling the "end of ideology" and attempting 
to construct the university as an apparently value-free institution-one that represented no particular interest or point of view, but instead the "vital-center."

And then in the 1960s, with the arrival of a more heterogeneous body of students within the academies, came the breakdown of a common academic language shared between students and the academic community-that was the point when the interestedness of certain apparently disinterested academicians was dramatically exposed. It was also a period in which the complicity of the academy with military violence, with the destructive technologies, with the war in Vietnam, was clear to everybody. I think that this is the crisis which we have inherited, and that literary theory, in its contemporary leanings, springs out of that period. Theory doesn't simply happen at any time in the history of a discipline. It happens when, for whatever historical reasons, there is a need for that discipline to become self-reflexive: when, for example, its traditional rationales have broken down and it needs some other rationale, when it needs to establish distance from itself. If it does that, as it had done in literary theory in the 1960s and since, if it becomes selfreflexive and no longer takes for granted a range of routinized assets but in some way estranges them, then it can have one of two functions. On the one hand, theory can simply reconfirm those practices, giving them an even more solid foundation. (I think some of the rather de-gutted imitations of marxism and structuralism and other fancy French products that found their way into Britain and the United States have been precisely a way of doing this by giving new injections of intellectual capital to a clapped-out industry.) Alternatively, you can raise the theoretical question in a way that will estrange those routinized practices to the point of changing them. Here we are talking less about the Yale School and more perhaps about Bertolt Brecht.

Currently there is a move in the academy to return to certain roots of German theory-athough not the tradition of Brecht and the Frankfort School, but to the tradition of hermeneutics variously associated with Husserl, Heidegger, Gadamer, and, if it becomes marxist, Habermas. Given your own references to Habermas, we were wondering whether you believe that hermeneutics - a marxist hermeneutics - can resolve the double bind of criticism you have described?

As a preliminary footnote here, as we begin to talk about German and French traditions, I think that it is interesting and somewhat ironic that the only role left to Anglo-American societies may be to serve as the meeting point of those two uncommunicating traditions. Since the French and Germans don't seem to talk to each other, then we might have to conduct the dialogue for them. Hermeneutics is not as popular or as discussed in Britain as it is in the United States, so I am always struck when I come to the U.S. to find that it is around and very much discussed, and I begin to ponder the political context to explain why this might be so. I think that some reasons 
seem to be fairly clear. Hermeneutics, it goes without saying, raises questions of fundamental importance about interpretation. It is also the case, however, that there are forms of hermeneutics which blend very easily with a kind of mild academic liberal humanism in this country which, in one sense, while apparently raising every conceivable question and being very anxious to question-raise, never seems to me to raise the questions which really hurt, and I think that may be one possibly accurate reason for the rapid absorption of certain forms of hermeneutics into the academy. I think that there is a problem about what hermeneutics is. Obviously it would be something of a category mistake to say that, as marxist criticism is produced, it is in fact a hermeneutics because, it seems to me, if hermeneutics is a reflection on interpretation it also engages questions common to a number of different critical approaches. I think it is therefore ironic that some academics and intellectuals do seem to want to make of hermeneutics, as it were, a third position or another position, one that can only be explained politically in terms of a rejection of (or a reaction to) such critical positions as marxism. Therefore, the first question one has to raise to a hermeneuticist, and we know that they love people raising questions so I'm sure they wouldn't be offended by this, is what exact status do you think your discourse has? And I think one problem there is that it is a discourse of a high level of generality, raising certain fundamental issues about the act of interpretation but standing at a rather disabling distance from ways of applying it in practical ways, both textually and politically. To raise yet another question: obviously hermeneutics has been politically interrogated, not least of all in the famous Gadamer-Habermas confrontation, and has raised questions of ideology and of the unproblematic assumption of a tradition in which hermeneutics seems complicitous. But beyond these questions there is the question of the politics of history, the political implications of and assumptions in, for example, the recovery of the past or the recovery of lost or semi-lost meaning. That is to say, it seems to me that the recovery or reconstruction of the meaning of past texts has to be a good deal more historical and political than most forms of hermeneutics one comes across seem to believe. I don't see why it should be a paradigm for cultural studies. And I think that in that sense the apparently neutral methodology of hermeneutics, which simply says that we should raise questions about the meaning of the past and its relation to the present, can actually license a kind of program or critical activity which continually swerves back to classical texts, which is continually interested in the relationship between past and present, but only conceived of in a particular way.

Now here I'd like to make two points. First, there are, after all, other ways of relating the past to the present than the most familiar ways of hermeneutics. There are the more dramatic and violent hermeneutics of Walter Benjamin, whose whole conception of the relationship between past and present is more political, more apocalyptic, and certainly more historically urgent 
than much of what one finds coming out of Germany now. Second, although marxists are of course concerned to question the relation between present and past meaning, I think for marxists these are questions always subordinated to another question- one that tends not to be asked by hermeneutics-namely, the question of the future. There is no view of the present or the past for marxism (or I think for other kinds of viable positions) which is not under the sign of a possible or desirable future. In one sense that may seem to be a strange thing to say because quite obviously the future, in a material sense, does not exist. But then neither does the past. What I mean is that in the making of such relations between past and future, we have to calculate-in where we are trying to get to in the first place. And it is this future-oriented dimension which I find lacking, not only in hermeneutical thinking, but in many forms connected to it.

You have been talking about a different vision of past and present in terms of the future, and thus raise the question of what you mean in your own work by "history" and "tradition." For example, in Criticism and Ideology you speak, as a marxist, of feeling acutely "bereft of a tradition." To quote you directly, you say that you feel, as a marxist, "a tolerated home guest of Europe, a precocious but parasitic alien." In Walter Benjamin: Or Towards a Revolutionary Criticism, on the other hand, you speak about a real distinction between history and tradition, in the Benjaminian sense of the difference between history, or the time of the ruling classes, and tradition, or the time of the oppressed and exploited. Finally in Literary Theory, you seem to fulfill the promise suggested in Walter Benjamin; that is, there seems to emerge in your work a certain tradition of marxist criticism. Could you comment a bit more on your views of history and tradition and the place of Literary Theory in forging a marxist tradition?

I would now want to look a bit critically at some of the generalizations I made in Criticism and Ideology, because often I was referring to the endemic empiricism and anti-intellectualism of British culture which resisted the sorts of traditions I believe I was-and now am-working within. I perhaps was not sufficiently aware that I was really only speaking of the tradition of theory, and that should never be for a marxist the first or major way of speaking of tradition. But after all there is an important and impressive tradition of British socialism, of working class and other forms of militancy and it was, perhaps, at that moment in the 1970s, part of my taking distance from Williams, that I really didn't dare take in the full weight of that. I wasn't really raising the question of how my own work related to that indigenous political tradition which my marxism tended to underplay - and I would like to correct the balance.

What I would want to say about tradition now from a marxist point of view is how important a concept it is. Perhaps this is more than stating the obvious. There was, after all, in the great explosion of radical thought and practice in the 1960s, and for all its futility, a valuable skepticism about the 
very idea of tradition which was sometimes all that one was trying to break away from. Thus a kind of eternal "nowness" finds later resonances not in the euphoric or hippie style, but in certain forms of contemporary left talk which seems to fetishize something called "present conjucture" where, as it were, everything rests on the roll of the dice in the present conjucture. Williams said long ago, I think in Culture and Society, that a society that can live only by contemporary resources is poor indeed. And I think that it is a structural effect of late bourgeois societies that they must repress history, because they must suppress alternative forms of history and also that their history tends to be the history of the same, tends to be the eternal return of the commodity in whatever fashionably varied guise that returns. So the first point would simply be to underline the vital nature of the concept of tradition for marxists. "We marxists," Trotsky once said, "have always lived in tradition." This of course is not to signal the uncritical or subservient relations of tradition which one finds, characteristically, in conservative thinking. I think, yes, Benjamin's distinction between history, meaning I suppose ruling class history and tradition or an alternative sort of histories, was very important to me because it made some sense of what I think is a problem with the British left, where there has been over the past ten or fifteen years a lot of working class, labour, and now feminist history, a lot of work in alternative history largely stemming from the History Workshop movement. Now, one of the criticisms made of that movement is that one can fall into the trap of seeing tradition, of seeing socialist or radical tradition, simply as an alternative in the sense of some suppressed but unbroken alternative continuity which, as it were, "ghosts" official history. And I think that Benjamin's own thinking about tradition, about the resources of the oppresed, is a way of breaking with that model. Because I think Benjamin's tradition is much less an alternative, ghostly history which could be blocked out whole and entire (as I think some labour historians and some feminist historians tend to think) than a set of, if you like, crises within history itself: a set of points of confrontation, of rupture or conflict, where you can see the outline of an alternative without having to parrot it. His tradition is then the assemblage of those moments which are always for him reassembled and reconstructed according to the demands of the present conjuncture. So I want to come back to the "present conjuncture" in that way but through that different perspective.

On yet another related subject, we wanted to ask you about your view of rhetoric, again drawing upon your views in Walter Benjamin and Literary Theory. In Walter Benjamin, you equate rhetoric with deconstruction and, with references to de Man, argue that rhetoric has retreated from politics and social practice and become a demystifier of ideology that itself proves the "final ideological rationale for political inertia." In Literary Theory, by contrast, you explicitly appropriate rhetoric for purposes of political criticism and an entirely different kind of discursive practice. Would you comment upon these two different views of rhetoric in your recent work? 
I think the apparent disparity emerges from the fact that there are different meanings of rhetoric and, indeed, I think the term is now certainly up for political grabs. Rhetoric is the site of struggle rather than a received definition. The rhetorical tradition itself is a set of quite varied traditions and what I was trying to pinpoint in the Benjamin book was really two, I think, quite politically incompatible notions of rhetoric. One is the use of the term to indicate discourse as power and performance and therefore as always conjunctural, as always inscribed within institutions. The other meaning of rhetoric, which since Nietzsche, is precisely the one identified in its latest form with de Man, views discourse as the play of tropes and calls into question not only the possibility of meaning itself but indeed the possibility of practice. That is to say, behind that Nietzschean insistence, that Nietzschean impulse inherited by many contemporary deconstructionists, lies a skepticism about the very coherence, about the foundedness of the concept of practice which cannot but be political. And again, this skepticism seems to me a coded response to or a polemic against materialist theories of practice. Now it clearly isn't our point to stand, as some marxists have done, on a concept of concrete practice which then is seen to solve all the problems. Clearly, practice is as difficult, ambiguous, and many-sided as anything else. I think that one has to understand the impulse behind that neo-Nietzschean attempt to deconstruct practice which, were it successful, would spell the death of any effective social transformation. If what is being said is simply a kind of therapeutic interrogation of certain over-simple, rather fetishized, notions of practice, then I think that marxists and other radicals can learn from deconstruction. But I don't think that this is what is being said. So I believe that one must return to a theory of rhetoric which, while not for a moment suppressing the problems of over-simplification or ambiguity, nevertheless begins from a grasp of the fact that rhetoric is indeed the nexus between discourse and power.

In your own work you are interested in the formal devices of literature, or what we might term "cultural production," and also with the ways in which these devices are activated in reception, or what we might call "cultural consumption." Does your interest in reception differ-and if so, in what way-from what has recently been rather broadly termed "reception theory"? And how would you respond to those attempts, as represented by the work of Tony Bennett and other marxist critics, to redirect reception theory in a more radical, more politically relevant, direction?

It may be interesting to see reception theory, like all other contemporary literary practices, again having its roots back in the 1960s. What we are really saying is that readers demand participation, just as within that climate demands for democratic participation of various kinds were clearly very strong. In other words it is part, and in principle a greater than usual part, of the dethroned mythology of literature. And I think it would be interesting to trace the development of that theory in the various institutional changes, 
demands, and programs which are characteristic of the 1960s. At the same time, I think that one has to say that not only has much standard European reception theory, and American reception theory for that matter, been criticized for positing a reader who is, very often, merely a function of contemporary reading formations and not a function of the whole political system as well. But it is clear that we are never simply readers, that we are never simply in the first place readers. Nor can we put magically into suspension the rest of our existence when we approach a text. There is a danger of a kind of left-academicism there, which would seem to presume that the classroom, if you like, is the only place in which meanings are constructed. And that obviously has to be challenged. The other problem in relation to the work of left reception theories, which you have touched upon in your question, is indeed the emphasis on consumption which can, from time to time, lead to a kind of carnival of consumerism or fetishism of the immediate reading conjucture. This can be just as narrowly dehistoricized in its own way as the more standard forms of bourgeois criticism. We are always more than the current reading conjuncture. It is partly a matter of how far we extend the word "reception." Now, a lot of the epistemological problems raised in those arguments are perhaps nearing a kind of solution or at least a consensus: for example, I think the meaning of the phrase "the text in itself" is now one that most of us would reject. It is clearly essentialistic. I think that there are equally certain forms of voluntarism of reading and interpretation, apparently based on a plurality of interpretations, which most of us would also want to reject. So I think there is a certain amount of common ground here too. But after those explorations are over I think that still one has to return to what is at stake for marxists: the ownership, or at least control of, the means of cultural production. That brings the focus to an important problem in being an oppositional critic. In one sense, working within the academy as an oppositional critic you are always in danger of being merely reactive to cultural work, or cultural phenomena, produced elsewhere. And that is structural to the academy, however much you may rightly talk of certain kinds of cultural production within the academy-and such talk is more widely done in the United States than it is in Europe. Then there is the question of when, for example, we take a film text and demystify it, or when we take a literary text and do an ideological analysis of it, of whether what we are doing is more valid. That is to say, whether such unmasking can reveal certain dominant meanings so as to prevent them from entering the general unconscious unchallenged. And that task is something vital, I think, which one has to defend. But at the same time it has its built-in limits and I don't think a radical critic can in the end be content with that task. We have to be talking about the production of cultural meanings, not only in terms of artifacts but also in terms of other forms of production of cultural meanings. This is the long-range perspective. Nonetheless, being an oppositional critic does not 
simply mean somebody who is in some way involved in academia. It does not, in the first place, mean somebody who takes the already fashioned product and submits it to a certain reading, however necessary that may be at the moment.

How would you respond, though, to the work represented by Bennett and others, and particularly to their argument that marxism shouldn't be concerned with questions of aesthetics or aesthetic value? Bennett says, for example, that "the object of marxist criticism is not that of producing an aesthetic, of revealing the truth about an already pre-established literature, but that of intervening within the social processes of reading and writing."

I think that once one begins to argue with Tony Bennett, once one begins to unpack the meaning of a phrase like "the social processes of reading and writing," then one would probably find oneself working with the kinds of issues which have been traditionally known as aesthetics. If Tony Bennett spells his position out more clearly or gives us a little more exemplary or concrete practice, then I think the sorts of questions or responsive devices and textual operations and effects that one would find oneself with in a properly political context-and that is the valuable point of it-really add up to what people really mean when they use the category "aesthetic." In other words, I think there is a danger in Bennett's work, and in any work of that kind, of implicitly subscribing to a bourgeois notion of aesthetics and then properly refusing it. Just as I think there is a danger in much deconstructive thinking of implicitly subscribing to utterly untenable metaphysical notions of truth, of art, of presence or ground, and then, of course, piously going on to deconstruct them. Obviously one could play that game for a long time. But the term "aesthetic" is, like many such terms, too valuable to be surrendered to the opposition without a struggle. I don't think that it is enough for a marxist critic to say, all right, you have your aesthetic discourses and you can keep them, we're going to do something else: call it politics, call it intervention in social processes or whatever. First of all, I don't think that the word "aesthetic" is that simple. Very often in his work, Tony Bennett tends to equate the aesthetic with a certain founding moment in the history of German thought, German idealism to be precise, and says quite properly that this is clearly untenable and so we want to do something else. But the word "aesthetic" seems to me a much more indeterminate and flexible word than that, one which really tries to analyze the specificity of whatever it is that is going on when people say, as they tend to, that they are responding to a work of art, rather than when they say they are digging the garden or taking a ride on a bus. It demarcates a certain kind of social practice. Now of course we know, and here Bennett and I are in agreement, that the boundaries of social practice are historically shifting in the extreme. Of course we want to reject essentialistic notions of aesthetics, but the word aesthetic covers a multitude of areas and responses and those, I think, 
cannot be abandoned. It would have been inconceivable to someone like Brecht to say, well I'm really not concerned with the aesthetic value of my play or poem, what I was really concerned with was whether it was politically effective. To which the simple answer would be: well, if it was boring, tedious, and badly done, how on earth could it have been politically effective? Those two questions for Brecht, of the political and the aesthetic, simply would not have been so disassociated. By the aesthetic he would have meant something like the production of certain kinds of dramatic and textual effects which made the political content of the work acceptable, interesting, exciting, and thought-provoking to particular audiences. So with that meaning of aesthetic I think one is talking from a properly leftist point of view.

One assumption is that you can culturally or politically activate texts that would otherwise be received in an apparently value-free or "disinterested" fashion. With other left reception theorists, such as Peter Bürger, however, the assumption is that radical meanings are always preempted by conservative institutions. So, in a sense, Bennett's work represents an attempt to break with a certain defeatism or incorporationist view of texts and institutions.

I think you're right. And I do think there is a way of using left reception theory to counter the most defeatist forms of incorporationist arguments because, as you point out, they surreptitiously assume that there is a standard or fixed meaning or value to the institution or the text. I very much admire Bennett's work in trying to break down those assumptions. At the same time, I think I would nevertheless agree with Stephen Heath's insistence that the argument about reader response or audience response very rapidly settled into a kind of unacceptable binary opposition between, on the one hand, the magically fixed "text in itself" and, on the other hand, as many different readers as you have texts. And I think Heath was quite right to point out that this was really a pseudo-position. Once one looks at the formations within which individuals are constituted as readers or viewers then the purely voluntaristic gates are thrown open.

I think Bennett's case is useful in shifting accent upon the calculation of textual effects, and so on. But at the same time, he sometimes pushes that to the point where it would seem mysteriously unpredictable what effects the text was likely to have in certain situations. I think it is at this point that I would want to disagree with Bennett and say that, given the formations within which readings are constituted, there is more predictability than some kind of pure reception theory would have us believe.

You have suggested that feminism represents today perhaps the most productive challenge to the dominant public sphere, particularly because feminism transgresses the boundaries of the academy and takes its primary impulse from a political movement embracing different groups aimed at countering a range of institutional practices. You 
have also argued that feminism is, in a very real sense, inseparable from marxism, or perhaps that marxism is inseparable from feminism, precisely because both speak from the margins of history, from a different tradition, and because both engage in a critique of power that is at once practical and theoretical. Given the partially sexist history of marxism, and given the marginality of both feminism and marxism, where do you see feminism in relation to marxist criticism today?

Let me first expand just a bit on the feminism and the public sphere idea. I mean by that not only that feminism is radical and does relate beyond the academy to a movement, a wider movement, and indeed takes its impulse from it. But what I mean by the public sphere more particularly is not just the public arena or, as it were, publicness as such (which is a broader definition of public sphere), but rather that area, that space, in which what we might perhaps adequately call politics and culture come together. I think that it is as part of the classical bourgeois public sphere that mediations exist between the public realm, or the realm of institutions, and forms of subjectivity that have their root in the domestic world which generates new forms of subjectivity. These are, in Habermas's phrase, "publically-oriented" and then pass over into the male-dominated public sphere to attain self-reflective formulation. I think it would be very interesting to trace the changing relations between the public sphere, the domestic sphere, and the stateparticularly for us as cultural workers, because culture seems to be the vital point of mediation between public and private. And if one looks at contemporary feminism in that light, then what I mean by it being an emergent set of elements towards a counter-public sphere becomes clear. It is concerned with problems of utility, relations between experiences or meanings formed in the private sphere and those formed in the political arena. Feminism, as does the classical public sphere, grasps these problems of subjectivity in political terms and it does put an important emphasis upon culture in the sense of language, experience, and so on, as part of a very necessary form of it. So feminism is one of a number of elements, one of the most important elements, as one can already see in Raymond Williams's term "emergent," that contributes to the creation of a possible counter-public sphere.

The problem with talking about feminism and marxism is that in the European context there is often, at least, a certain assumption that feminism and marxism, or feminism and socialism, in some way belong together. For all the real theoretical and political differences, they inhabit an area on the left. They have common interests whatever the formal history that links them. What little work I've done in that area, my book on Richardson particularly, really comes out of that kind of perspective, which is then obviously very different from what in Britian began as "radical feminism." By radical feminism I mean that form of feminism that no more sees any particular necessity to address questions of class struggle than do many other forms of politics. What I would hope for is some kind of convergence 
between marxists and feminists which would not be a mutual appropriation, but which would be worked out within the sphere of political activity; that is, within the realm of trying to construct a counter-public sphere. And as is so often with theoretical questions and political differences, such practice would seem to allow for such clarification. I think that one reason feminism is so important to socialism, and to traditional forms of it, is that socialism must be about not only a handing over of power, but it must be a translation of the very meaning of power. Any kind of marxism or socialism that stops before that point, as in the post-capitalist bureaucracies of Eastern Europe, would be sorely distorted and disabled. I don't think it is a question of ceasing to talk altogether, as happens in certain familiar forms of so-called participatory democracy (whether of a socialist or feminist kind) because participatory democracy is a form of power just like any other form of power. The task is to change the meaning of power itself-even to the point where we could now, within our present discourse of power, be able to recognize or identify what might pass for power in that kind of society. I think that really is the goal and to that extent feminism, if I might speak honestly from a marxist position, is a close reminder of that revolution within the revolution which signals what is still to be done: it signals to what extent the even productive political concepts or strategic concepts are still in complicity with the kind of rationality, the kind of power structure, that feminism is ultimately out to destroy. All of that for me is its major importance. And what I have tried to do in the book on Richardson was less to write a critical study of Richardson than to indicate a way in which feminism, a certain kind of post-structuralism, and materialism could come together without mutual appropriation. I believe that is possible. But I also believe that it is fearsomely difficult in the actual political arena, given the necessary vigilances and mutual suspicions that now exist between socialist men and women. On the other hand, one way in which these difficulties might be negotiated is by showing, if only at the theoretical level, that something can be done which is not simply an appropriation, and that has quite rightly been feared by feminists.

In the conclusion to Literary Theory, you seem to broaden the structuralist concern with decentering the subject by calling for a radical decentering of the object of literary criticism. To phrase this a bit differently, you seem to suggest the need to redefine the concept of literature in such a way as to transgress prevailing disciplinary boundaries. Could you elaborate upon what you think the effects of such a decentering would be, both in the academic institution and, at least potentially, in the public sphere?

I think it is difficult to talk about this now because of the real, practical, short-term problems involved in any radical transformation of the academy. Certainly this is so in Britain, where one always feels a sense of incongruity in launching ambitious radical perspectives when what one is really worried about is people's jobs, cuts in the student population, the savage cuts in 
funding, and so on. But I think there are different ways you can go in that situation, different strategic ways. I have even heard it seriously suggested on the left, by a colleague of mine in Britain, that what we ought to do is defend the concept of high literature to the death against the philistinism of Thatcher. And, of course, one can understand that type of thinking. I think that it is the wrong approach nevertheless because the phenomenon of Thatcherism, or its equivalent in the United States, is so challenging that, as radicals, we have to try to think it through to the end in order to have the kind of vision and energy to oppose it. I don't think, however difficult the short-term negotiations are, that you can really oppose that virulent form of class society with anything less than what you ultimately desire. That is why I think there is a point now, if only strategically, in trying to work out what it is we would want in the end because that would provide us with a set of guidelines for what we are doing at the moment. And I think that it does have to be a deconstruction of the institution. Where I find deconstructive thought most useful is in its approach to the question of transforming modern institutions. I am very struck by the manifesto, presumably written by Jacques Derrida for the newly founded Collège International de Philosophie. Whatever the political difficulties, whatever the marginalization of the academy, Derrida and his colleagues really do seem to be working towards a deconstructed institution where, as it were, the transgression of boundaries, not only between subject-areas but between academic and social practices, would be built into the whole institution. I think that we have to find some kind of equivalent to work toward in the universities that does in the end mean the replacement of the current divisions of intellectual labour by some organized conception that examines the effects of all forms of discourse in terms of the power context in which they now exist. And that will mean some new kind of rhetoric, simply because of the emormous importance of those signifying processes. It seems to me that in a postGramscian era of bourgeois society there is no way to ignore the central role played by symbolic processes of all kinds, from advertising to the unconscious, in the reproduction of bourgeois power. Curiously, in one sense the radical critique now involved in the cultural field is a modest and marginal presence-and in a certain way that is appropriate. But what is at stake, in the end, is the unlocking of certain very powerful, very unconscious forms of signification and the construction of new forms of identity and the subjects to go with them. There is a sense, then, that what we are trying to do now, if in a besieged and defensive way, is prefiguring a very important future. And I think one should put that quite sharply by saying that without the fight on the cultural and ideological front it is unlikely that we are going to be able to unlock some of those lethal armed struggles that now politically and critically confront us. 